\title{
The Stretta procedure versus proton pump inhibitors and laparoscopic Nissen fundoplication in the management of gastroesophageal reflux disease: A cost-effectiveness analysis
}

\author{
Dan Comay $\mathrm{MD}^{1}$, Viviane Adam $\mathrm{MSc}^{2}$, Eduardo B da Silveira MD MSc ${ }^{1}$, \\ Wendy Kennedy $\mathrm{PhD}^{3}$, Serge Mayrand $\mathrm{MD}^{1}$, Alan N Barkun MD MSc ${ }^{1,2}$
}

D Comay, V Adam, EB da Silveira, W Kennedy, S Mayrand, AN Barkun. The Stretta procedure versus proton pump inhibitors and laparoscopic Nissen fundoplication in the management of gastroesophageal reflux disease: A costeffectiveness analysis. Can J Gastroenterol 2008;22(6):552-558.

BACKGROUND: The Stretta procedure is an endoscopic therapy for gastroesophageal reflux disease.

OBJECTIVE: To evaluate the cost-effectiveness of the Stretta procedure and that of competing strategies in the long-term management of gastroesophageal reflux disease.

METHODS: A Markov model was designed to estimate costs and health outcomes in Canadian patients with gastroesophageal reflux disease over five years, from a Ministry of Health perspective. Strategies included the use of daily proton pump inhibitors (PPIs), laparoscopic Nissen fundoplication (LNF) and the Stretta procedure. Probabilities and utilities were derived from the literature. Costs are expressed in 2006 Canadian dollars. Units of effectiveness were symptom-free months (SFMs) and quality-adjusted life years (QALYs), using a five-year time horizon.

RESULTS: In the analysis that used SFMs, the strategy using PPIs exhibited the lowest costs ( $\$ 40$ per SFM) and the greatest number of SFMs, thus dominating both the LNF and Stretta systems. But the cost-effectiveness analysis using QALYs as the measure of effectiveness showed that PPIs presented the lowest cost-effectiveness ratio, while both the LNF and Stretta strategies were associated with very high incremental costs (approximately $\$ 353,000$ and $\$ 393,000$, respectively) to achieve an additional QALY. However, the PPI strategy did not dominate the two other strategies, which were associated with better effectiveness.

CONCLUSIONS: If SFMs are used as the measure of effectiveness, PPIs dominate the Stretta and LNF strategies. However, if QALYs are used, the PPIs still present the lowest cost and LNF gives the best effectiveness. Regardless of the units of effectiveness or utility used in the present cost analysis, an approach of prescribing PPIs appears to be the preferred strategy.

Key Words: GERD; Proton pump inhibitors; Stretta procedure
Technique de Stretta versus inhibiteurs de la pompe à protons et fundoplication laparoscopique de Nissen dans la prise en charge du RGO : Analyse coût-efficacité

\begin{abstract}
HISTORIQUE : La technique de Stretta est un traitement endoscopique pour le reflux gastro-œsophagien (RGO).

OBJECTIF : Comparer les rapports coût-efficacité de la technique de Stretta et de stratégies concurrentes dans la prise en charge à long terme du RGO.

MÉTHODES : Un modèle de Markov a été conçu pour estimer le coût et l'issue du traitement du RGO chez des patients canadiens sur une pé riode de cinq ans, du point de vue du ministère de la Santé. Les stratégies comparées étaient donc : traitement quotidien par inhibiteurs de la pompe à protons (IPP), fundoplication laparoscopique de Nissen (FLN) et technique de Stretta. Les probabilités et utilités proviennent de la littérature, les coûts sont exprimés en dollars canadiens de 2006. Les unités d'efficacité étaient le nombre de mois sans symptôme (MSS) et les années de vie pondérées par la qualité (ou QALY, pour quality-adjusted life years) sur un horizon temporel de cinq ans.

RÉSULTATS : Dans l'analyse qui portait sur les MSS, les IPP ont été la stratégie la moins coûteuse (40 \$ par MSS) et ils ont donné lieu au plus grand nombre de MSS, ces résultats se révélant supérieurs à ceux de la FLN et de la technique de Stretta. Mais l'analyse coût-efficacité selon les QALY a révélé que les IPP présentaient le rapport coût-efficacité le plus bas, tandis que la FLN et la technique de Stretta ont été associées à des coûts différentiels extrêmement élevés (environ 353000 \$ et 393000 \$, respectivement) pour l'ajout de QALY additionnelles. Par contre, la stratégie par IPP n'a pas dominé les deux autres approches, qui ont été associées à une plus grande efficacité.

CONCLUSION : Si les MSS sont utilisés comme mesure de l'efficacité, les IPP sont supérieurs à la technique de Stretta et à la FLN. Par contre, si ce sont les QALY qui sont utilisées, les IPP représentent la stratégie la plus abordable et la FLN donne les meilleurs résultats. Peu importe les unités d'efficacité ou la mesure d'utilité employée dans la présente analyse de coûts, l'approche qui consiste à prescrire des IPP semble à privilégier.
\end{abstract}

${ }^{1}$ Division of Gastroenterology; ${ }^{2}$ Department of Epidemiology, McGill University; ${ }^{3}$ Faculty of Pharmacy, Universite de Montreal, Montreal, Quebec Correspondence: Dr Alan N Barkun, Division of Gastroenterology, McGill University Health Centre, Montreal General Hospital, 1650 Cedar

Avenue, \#D7-148, Montreal, Quebec H3G 1A4. Telephone 514-934-8309, fax 514-934-8531, e-mail alan.barkun@muhc.mcgill.ca Received for publication October 23, 2007. Accepted February 5, 2008 
G astroesophageal reflux disease (GERD) is one of the most prevalent medical disorders in the United States, affecting 19 million people chronically (1), and generating an annual cost of $\$ 40$ billion in health care expenditures (2).

In patients with uncomplicated reflux symptoms, the mainstays of treatment are proton pump inhibitors (PPIs) and antireflux surgery (3). Endoscopic therapies, such as the Stretta procedure, may potentially reduce or eliminate long-term drug use without the expense or complications of surgery (4).

The Stretta procedure (Curon Medical, USA) is a minimally invasive, endoscopic treatment of GERD in which radiofrequency energy is applied to the gastroesophageal junction (5). In principle, controlled injury causes scarring and stricturing of the lower esophageal sphincter, limiting free reflux of gastric contents (5). Damage to the gastroesophageal junction may also reduce nociception and the vagal impulses that drive transient lower esophageal sphincter relaxations (5).

A previous controlled study (6) of the Stretta procedure showed significant reductions in mean heartburn scores and quality-of-life measures after six months relative to a sham arm. Further, prospective studies of the Stretta procedure suggest that the response may persist for up to three years $(7-10)$.

To date, no prospective trials comparing medical, surgical and endoscopic treatments of GERD have been published. Thus, third-party payers examining the relative costs and benefits of GERD therapies must draw their assessments from alternate sources. A decision model examining the costs and health outcomes of GERD treatment will therefore provide valuable insight into the cost-effectiveness of the different competing strategies.

\section{METHODS}

\section{Model design}

A Markov model was designed to simulate the management of patients with uncomplicated GERD. A Markov model is a mathematical construct containing multiple decision nodes and health states that estimate outcomes based on userdefined, repeated risks over time (11). The model was developed using 2005 TreeAge Pro Suite software (TreeAge Software Inc, USA).

\section{Model cohort}

The study population included adult patients with GERD, documented by an abnormal $24 \mathrm{~h} \mathrm{pH}$ study, who were at least partially responsive to PPIs. The following criteria were met before enrolment: small (smaller than $2 \mathrm{~cm}$ ) hiatal hernia, absence of significant esophagitis, stricture, Barrett's esophagus or malignancy, and normal esophageal manometry. All patients were symptomatically stable and generally medically fit for endoscopic or surgical antireflux treatments.

\section{Model structure}

Three strategies were compared: medical therapy with oncedaily PPI therapy, surgical therapy with laparoscopic Nissen fundoplication (LNF) and endoscopic therapy with the Stretta procedure (Figure 1). The model's time horizon was five years, with a cycle length of six months to best reflect available evidence from fully published, controlled trials.

Medical arm (PPI): Patients in this arm received a once-daily PPI (omeprazole $20 \mathrm{mg}$ tablets). Based on previous trial experiences, patients were presumed to be compliant with and tolerant of their medications. In the base cases, patients were

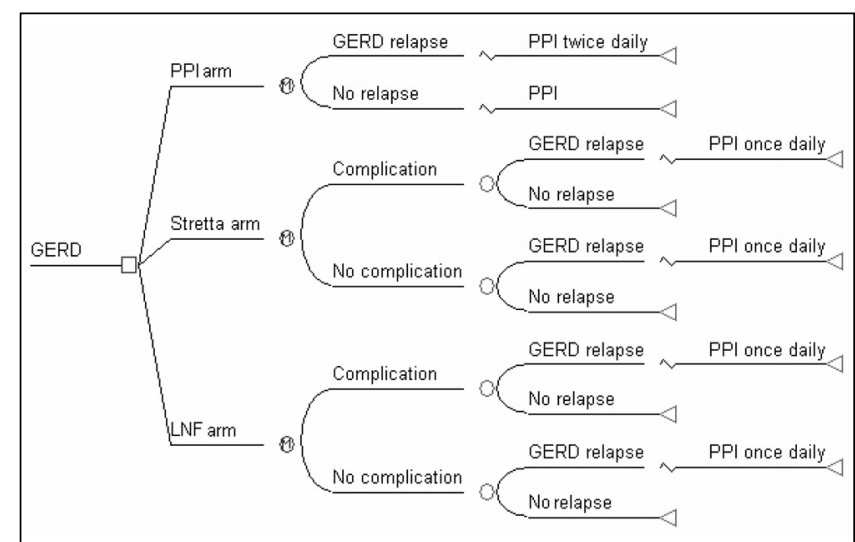

Figure 1) Simplified tree structure depicting three management strategies for gastroesophageal reflux disease (GERD). LNF Laparoscopic Nissen fundoplication; PPI Proton pump inhibitor

assumed to be symptom-free on medications; however, symptom relapse requiring twice-daily PPI dosing was incorporated into the model as part of a sensitivity analysis (see below).

Surgical arm (LNF): Patients in this arm underwent LNF. Patients who were symptomatic immediately after surgery ('LNF failures') or who developed symptom recurrence during follow-up were managed with once-daily PPI use. The model captured in-hospital and early postoperative complications that required intervention (namely esophageal stricture). Non-GERD complications, such as the gas-bloat syndrome, were not included. Complication rates did not have an impact on treatment response. Neither surgical revisions nor mortality were included.

Endoscopic arm (Stretta): Patients in this arm underwent the Stretta procedure as per published protocols (6). Health states were derived from the prospective cohort and controlled trial experience. Postprocedural complications that required intervention (namely bleeding esophageal ulcer) were included in the model. Patients not responding to the Stretta procedure ('Stretta failures') or subsequently developing symptoms during follow-up were treated with once-daily PPIs. As with the LNF arm, treatment response rates were not influenced by previous complications, and mortality was not included in the model.

\section{Transition probabilities}

All model parameters were derived from the medical literature, and fixed-time probabilities (such as annual rates) were converted to six-month transition estimates using established methods (12) (Table 1). A MEDLINE search of studies published before November 2004 was conducted using the terms "gastroesophageal reflux", "fundoplication" and the keyword "Stretta". Also, published reviews and key conference abstracts were hand-reviewed for relevant material.

\section{Health utility estimates}

Symptom-free months (SFMs) was one of two units of effectiveness adopted. The values are directly based on the probabilities of success and relapse shown in Table 1 . In addition, quality-adjusted life years (QALYs) experienced in a health state were also used as the unit of effectiveness (utility) for a separate analysis. QALYs were estimated by multiplying the time spent in a specific health state by its associated utility 
TABLE 1

Base case estimates and ranges for transition probabilities and utility weights used in the model

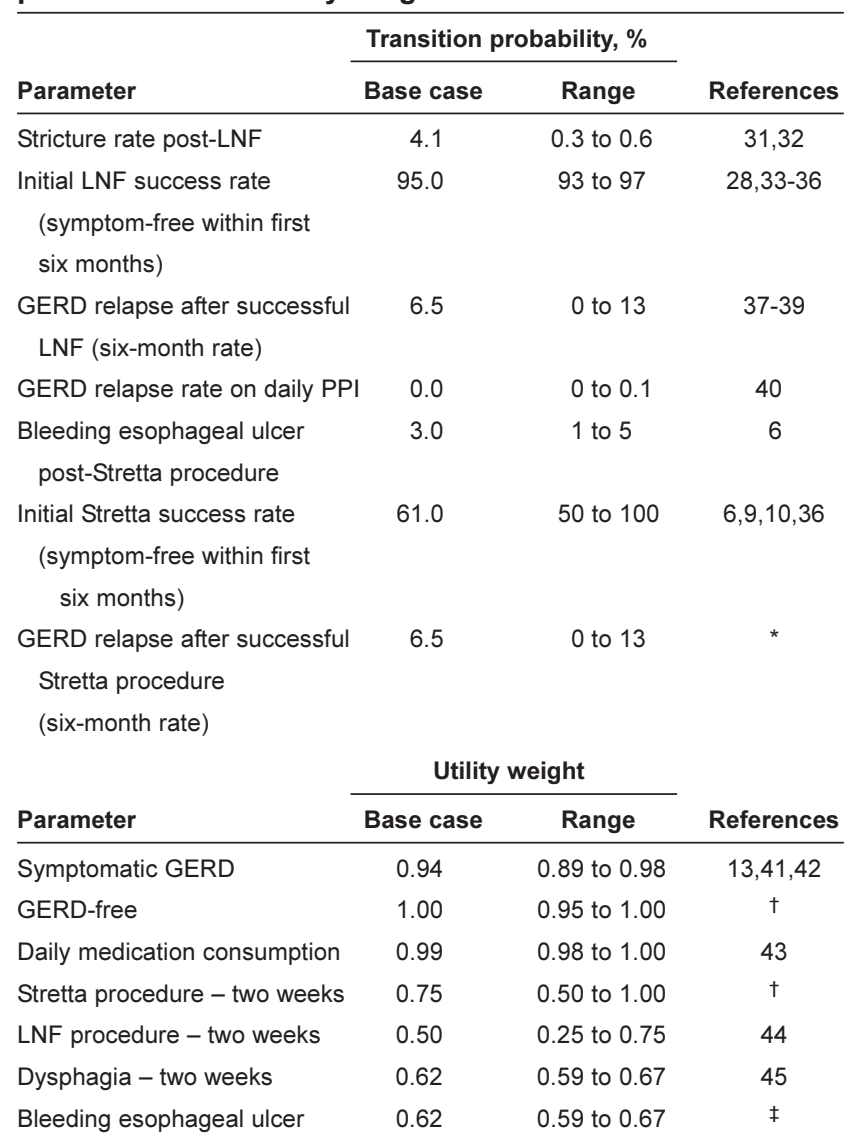

*The authors assumed that the probability was the same as laparoscopic Nissen fundoplication (LNF); †Assumption by the authors; $¥$ The authors assumed that the probability was the same as dysphagia. GERD Gastroesophageal reflux disease; PPI Proton pump inhibitor

weight. Symptom-free health had a utility weight of 1.0, with all other states assigned a disutility of varying degrees. Utility weights in the present model were derived from a variety of published sources, including those derived from expert consensus and from validated statistical methods (Table 1). The principal utility value for GERD was adapted from a Canadian study (13). The transient disutility for undergoing the Stretta procedure was assumed to be similar to esophageal dilation by consensus (Dan Comay, Alan N Barkun, Serge Mayrand). QALYs were discounted by 3\% over the five-year study period, as per established guidelines (14).

\section{Cost-effectiveness determination}

For each intervention, the clinical end points examined were time without GERD symptoms and reduction in PPI usage. Final health outcomes included SFMs and QALYs, with the model rolled back successively for each measure of effectiveness. Strategies were ranked in descending order by total costs, and comparisons were made with the next most costly, nondominated treatment alternatives (dominated strategies are less effective and more costly). Incremental costeffectiveness ratios were calculated for all nondominated strategies.
TABLE 2

Base case estimates and ranges for costs and length of stay used in the model

\begin{tabular}{|c|c|c|c|}
\hline \multirow[b]{2}{*}{ Parameter } & \multicolumn{2}{|c|}{ Cost, \$ } & \multirow[b]{2}{*}{ Reference } \\
\hline & Base case & Range & \\
\hline Omeprazole $20 \mathrm{mg}$ tablet & 1.25 & 1 to 6 & 17 \\
\hline Hospitalization for LNF & $5,761.00$ & 4,859 to 10,624 & 40 \\
\hline Surgical fee for LNF & 550.60 & 275 to 1,102 & 18 \\
\hline Anesthesia fee & 225.47 & 112 to 451 & 18 \\
\hline Surgical consult fee & 81.60 & 40 to 164 & 18 \\
\hline Outpatient surgical follow-up fee & 29.20 & 14 to 59 & 18 \\
\hline Inpatient surgical follow-up fee & 29.20 & 14 to 59 & 18 \\
\hline Esophageal dilation fee & 30.65 & 15 to 62 & 18 \\
\hline Hospital cost for endoscopy & 185.00 & 92 to 370 & 18 \\
\hline Endoscopy fee & 102.75 & 51 to 206 & 18 \\
\hline Stretta catheter cost & $1,398.00$ & 699 to 2,796 & 21 \\
\hline Stretta guidewire cost & 67.00 & 33 to 134 & 21 \\
\hline $\begin{array}{l}\text { Annual equivalent expenditure } \\
\text { for Stretta module* }\end{array}$ & $7,232.00$ & 3,616 to 10,848 & 21 \\
\hline Stretta procedure fee & 146.60 & 73 to 294 & 18 \\
\hline Outpatient medical follow-up fee & 29.20 & 14 to 59 & 18 \\
\hline Physician fee for UGIB & 171.40 & 85 to 343 & 18 \\
\hline Hospitalization for UGIB & $4,124.00$ & 2,150 to 6,661 & 19 \\
\hline Inpatient medical follow-up & 29.20 & 14 to 59 & 18 \\
\hline $\begin{array}{l}\text { Weekly frequency of the use of } \\
\text { the model, } n\end{array}$ & 5 & 2 to 10 & $t$ \\
\hline $\begin{array}{l}\text { Yearly frequency of the use of } \\
\text { the model, } n\end{array}$ & 50 & 45 to 52 & $\dagger$ \\
\hline Length of stay for UGIB, days & 4.6 & 1 to 10 & 46 \\
\hline Length of stay for LNF, days & 4.8 & 3 to 10 & 19 \\
\hline
\end{tabular}

All costs are expressed in 2006 Canadian dollars. *Based on an acquisition cost of $\$ 36,002$ (ie, a value of $\$ 28.20$ per use); ${ }^{\dagger}$ Assumption based on the information given by the manufacturer and based on the use at the Montreal General Hospital (Montreal, Quebec). LNF Laparoscopic Nissen fundoplication; UGIB Upper gastrointestinal bleeding

Cost data

General considerations: In Canada, health care (including physician remuneration) is publicly funded and is administered locally by provincial ministries. Subsidization of prescription drugs varies by province, and is subject to inclusion in local formularies. The perspective of a provincial Ministry of Health (third-party payer) was adopted for direct medical costs (drug, physician and hospital costs) (Table 2). All costs are expressed in 2006 Canadian dollars and are discounted by $3 \%$ over the five-year study period, as per established guidelines $(15,16)$.

Drug costs: The generic price of omeprazole $20 \mathrm{mg}$ tablets, derived from a national database (17), was used. The price does not include the pharmacist's professional fees. Boundaries for price ranges used in the sensitivity analysis are presented in Table 2. Although drug costs used reflected available prices at the time of the study, the potential for future, less expensive PPI equivalents and cheaper generic drugs was addressed in an a priori sensitivity analysis.

Physician remuneration: In Canada, physicians bill the provincial Ministry of Health on behalf of patients for services provided. Consultation and procedural fees used in the model were derived from the Ontario Ministry of Health and Long-Term Care Schedule of Benefits (18). Current fee 
TABLE 3

Results of the base case analysis for the outcome of symptom-free months

\begin{tabular}{lcccccc}
\hline Strategy & Cost, \$ & IC, \$ & Effectiveness* & IE* $^{*}$ & CER $^{\dagger}$ & ICER $^{\dagger}$ \\
\hline PPI arm & $2,394.10$ & - & 60.00 & - & 39.90 & - \\
Stretta arm & $3,239.30$ & 845.20 & 56.77 & -3.23 & 57.06 & Dominated \\
LNF arm & $7,394.70$ & $5,000.60$ & 58.32 & -1.68 & 126.80 & Dominated
\end{tabular}

All costs are expressed in 2006 Canadian dollars. *Units are symptom-free months; †Units are \$ per symptom-free month. CER Cost-effectiveness ratio; IC Incremental cost; ICER Incremental cost-effectiveness ratio; IE Incremental effectiveness; LNF Laparoscopic Nissen fundoplication; PPI Proton pump inhibitor

schedules do not reimburse directly for the Stretta procedure. However, in anticipation of future inclusion, a fee equal to esophagoscopy/gastroscopy for active bleeding with removal of a foreign body was used. All ranges of sensitivity analyses for physician fees were calculated by subtracting or adding one-half of the point estimate value (Table 2).

Hospital-related costs: Health care resource profiles were constructed for each health state, and costs per resource unit were adapted from various sources (see below). Hospital costs (excluding endoscopy) were extracted from the Canadian Institute for Health Information (CIHI) database (19). The $\mathrm{CIHI}$ is a national, not-for-profit organization that maintains a comprehensive health information system, which includes patient and hospital data from a discharge abstract database. CIHI data do not include physician fees. Discharges from acute care hospitals are assigned both a case-mix group identifier (similar to American diagnosis-related groups) and a complexity level based on the health status of the patient. The low and high bounds for the range of sensitivity analysis were based on lower and higher complexity levels for the diagnosis in the CIHI database (19). Costs for gastroduodenoscopy were previously reported from an activity-based costing study conducted in a major academic centre in Quebec (20). Boundaries for sensitivity analysis are presented in Table 2.

Stretta costs: Total costs for the Stretta procedure were divided among three costing units: endoscopy costs, disposable equipment costs and the per-use costs of the lightemitting Stretta module (21). The purchase price for all disposable instruments (Stretta catheter and guidewire) were drawn from the literature (21). All United States costs were converted into Canadian dollars. The acquisition cost of the Stretta module was updated using the consumer price index given by the bank of Canada for 2006 (www.bankofcanada.cal en/index.html), and was amortized over the model's time frame (assuming five uses per week, 50 uses per year for five years. These values of frequency were tested in the sensitivity analysis [Table 2]). Upper and lower margins for the sensitivity analysis were calculated by subtracting or adding onehalf of the base case cost.

\section{Sensitivity analysis}

Deterministic analysis: To test the effects of variability in the choice of model parameters, one-way sensitivity analyses were performed using a range of values obtained from the literature, or were determined a priori by consensus (Dan Comay, Alan N Barkun, Serge Mayrand) when base case probabilities were less established (Tables 1 and 2). Sensitivity analysis specifically

\section{TABLE 4}

Results of the base case analysis for the outcome of quality-adjusted life years

\begin{tabular}{lrccccc}
\hline Strategy & Cost, \$ & IC, \$ & Effectiveness* $^{*}$ & IE $^{*}$ & CER $^{\dagger}$ & ICER $^{\dagger}$ \\
\hline PPI arm & $2,394.10$ & - & 4.6357 & - & 516.45 & - \\
Stretta arm & $3,239.30$ & 845.20 & 4.6381 & 0.0024 & $698.41352,925.10$ \\
LNF arm & $7,394.70$ & $4,155.40$ & 4.6487 & 0.0106 & $1590.71392,432.48$
\end{tabular}

All costs are expressed in 2006 Canadian dollars. *Units are quality-adjusted life years; †Units are \$ per quality-adjusted life year. CER Cost-effectiveness ratio; IC Incremental cost; ICER Incremental cost-effectiveness ratio; IE Incremental effectiveness; LNF Laparoscopic Nissen fundoplication; PPI Proton pump inhibitor

targeted the probability and cost assumptions that altered costeffectiveness results by at least 20\% (22).

Probabilistic analysis: Probabilistic analyses were also conducted to further assess the impact of uncertainty in model estimates by adapting reference ranges to beta and normal distributions for cost inputs and transition probabilities (23). Using Monte Carlo stochastic methods, values were sampled at random per distribution over 10,000 unique model simulations (24).

Cost-effectiveness acceptability curves: Cost-effectiveness acceptability curves were constructed to better interpret cost effectiveness (25). Derived from Monte Carlo simulations, cost-effectiveness acceptability curves represent the proportion of incremental cost and incremental effect points where the intervention is cost-effective over varying willingness-topay (WTP) values. WTP thresholds are the maximum ceiling costs per unit of benefit below which a payer deems an intervention to be cost-effective (26).

\section{Base case analysis}

\section{RESULTS}

Administering PPI therapy was the cheapest strategy among the three tested in the present model, and was the dominant strategy according to the analysis, which used SFM as an effectiveness measure. Table 3 shows that PPI treatment was the most effective strategy, with a mean cost-effectiveness ratio of approximately $\$ 40$ per SFM. The other two strategies were dominated by the PPI treatment, because they were less effective and more expensive.

For the analysis in which effectiveness was measured in QALYs (Table 4), the PPI strategy presented the lowest value of QALYs ( 0.013 less than the highest value obtained by the LNF strategy). However, the PPI arm still had the lowest costeffectiveness ratio ( $\$ 516.45$ per QALY). The incremental costeffectiveness ratios of the other two strategies were both above $\$ 350,000$ per additional QALY.

\section{Sensitivity analysis}

The results of the present study were only sensitive to the price of omeprazole (20 mg tablet) when it increased to $\$ 2.20$. Indeed, the sensitivity analysis showed that, with regard to the SFM analysis, when the price of omeprazole rose over $\$ 2.40$, the Stretta strategy was associated with the lowest costeffectiveness ratio (Figure 2), and the LNF strategy was still dominated.

With regard to the QALYs analysis, the Stretta strategy also became the preferred option according to the costeffectiveness ratios when the price of omeprazole increased to more than $\$ 2.20$ (Figure 3). 


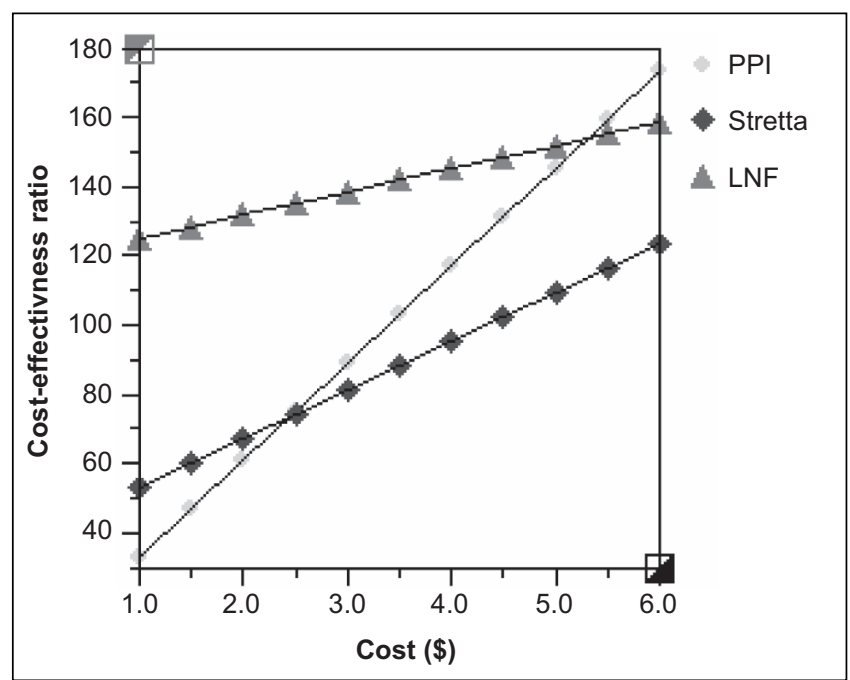

Figure 2) Sensitivity analysis on the cost of an omeprazole $20 \mathrm{mg}$ tablet according to symptom-free months. All costs are expressed in 2006 Canadian dollars. LNF Laparoscopic Nissen fundoplication; PPI Proton pump inhibitor

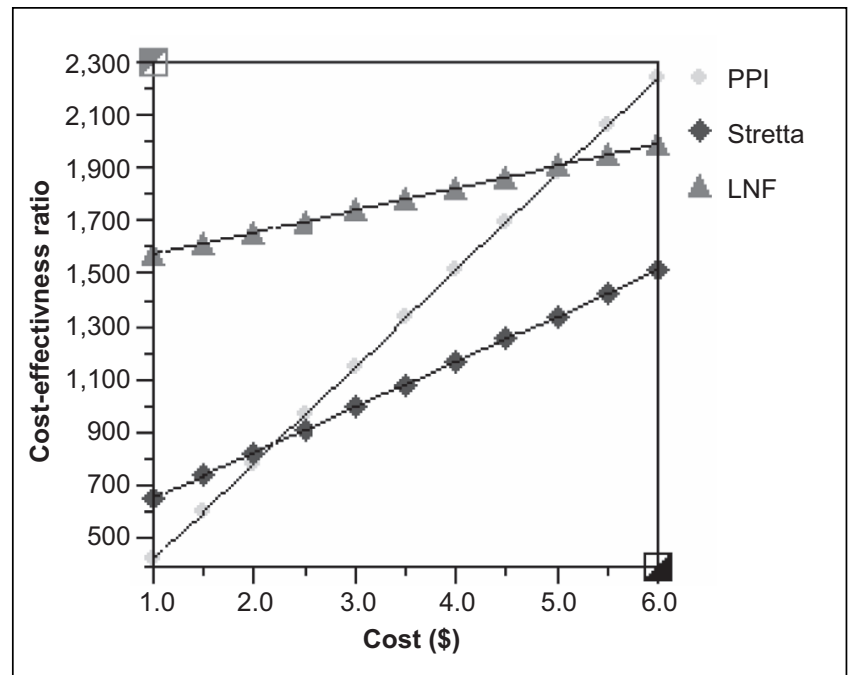

Figure 3) Sensitivity analysis on the cost of an omeprazole $20 \mathrm{mg}$ tablet according to quality-adjusted life years. All costs are expressed in 2006 Canadian dollars. LNF Laparoscopic Nissen fundoplication; PPI Proton pump inhibitor

\section{Probabilistic analyses}

The Monte Carlo analysis was performed, generating 10,000 simulations. The values were almost unchanged across the set of simulations based on the distribution of the probabilistic variables. Mean and median values for the cost and effectiveness measures obtained by the 10,000 simulations were the same as the mean values presented in the results of the present study (Tables 3 and 4), confirming their stability robustness.

The results of the probabilistic analysis for the SFM and QALY units of effectiveness are displayed graphically as acceptability curves in Figures 2 and 3, respectively.

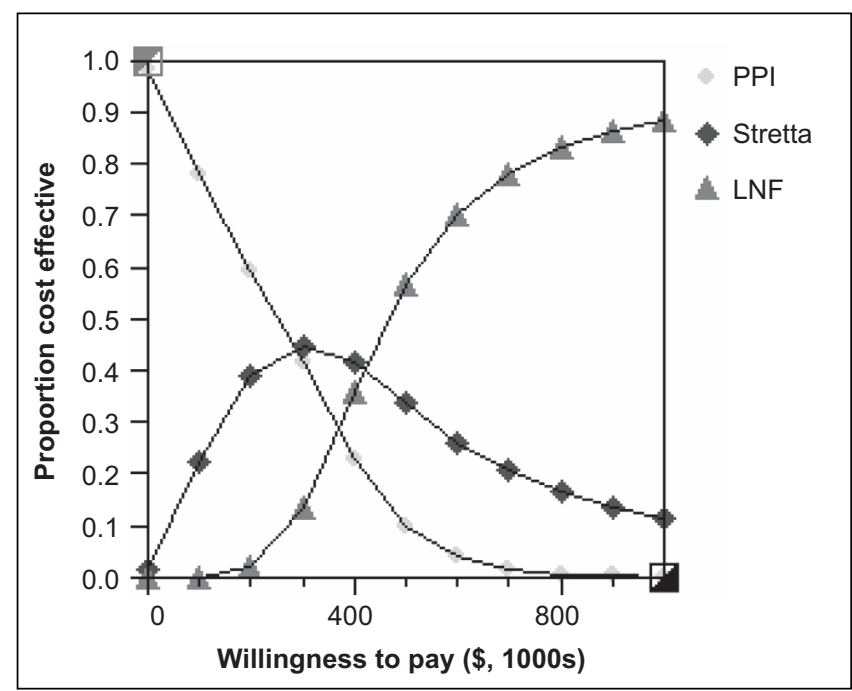

Figure 4) Cost-effectiveness acceptability curve for the analysis measuring effectiveness as quality-adjusted life years. All costs are expressed in 2006 Canadian dollars. LNF Laparoscopic Nissen fundoplication; PPI Proton pump inhibitor

Whatever the amount of WTP, the PPI strategy was most likely to be cost-effective when SFM was used as a unit of effectiveness. The acceptability curves for the QALY analysis (Figure 4) show that under a WTP of $\$ 350,000$, the PPI strategy is also most likely to be cost effective. For a WTP between approximately $\$ 350,000$ and $\$ 400,000$, the Stretta option would most likely be preferred. Above $\$ 400,000$, it is the LNF strategy that displays the highest probability of being cost effective.

\section{DISCUSSION}

As with all cost-effectiveness analyses, limitations based on model assumptions reflect unknowns or inconsistencies in the literature, and deserve further discussion. First, for patients on daily PPI therapy, a step down to less costly or indemand treatment strategies were not studied. Although selected patients with GERD may tolerate these strategies, we chose to examine a population having sufficient burden of disease to require daily PPI medication. Indeed, it is unlikely that endoscopic or surgical options would be considered for patients with symptoms controlled by more infrequent or less potent pharmacotherapy. Second, postfundoplication symptoms, such as diarrhea and gas-bloat syndrome, were not modelled, because these complications typically resolve within six months with lifestyle and dietary changes (27). We acknowledge that, for some patients, these complications may be more bothersome than the inciting GERD. If anything, this approach favours the calculated effectiveness and utilities of the LNF and Stretta options in the model. Third, postoperative mortality was not considered in the model, based on a recent meta-analysis of randomized, controlled trials (28). These studies, however, amalgamated results from large-volume, academic centres and may not reflect rates in smaller community settings. Therefore, caution should be used before generalizing these assumptions to local centres. Cumulative experience to date has shown that the Stretta procedure is reasonably safe, with 
lessening frequency and severity of complications, particularly in experienced hands (29).

The conclusions favour the PPI strategy, because in the case of SFM, it is dominant and in the case of QALYs, the other two options display incremental cost-effectiveness ratios much greater than what would usually be deemed a cost-effective choice for decision-makers. Nonetheless, there are differences in the results when using SFM versus QALYs as measures of effectiveness or utilities, which may reflect disparate sources in the literature for the different estimates, and perhaps, patient populations that may have varied in certain characteristics that are difficult to characterize. The 'frontloaded' nature of the benefits attributable to the endoscopic and surgical treatments may also be an explanation when compared with the more prolonged disutility associated with the ongoing consumption of PPIs.

By necessity, several United States cost inputs were converted and used in our Canadian model when comparable Canadian data were not available. Although simple currency conversion may not accurately reflect differences in transnational health care resource costing and the proportioning of certain costs (30), we accounted for these variances in the sensitivity analyses.

\section{REFERENCES}

1. Tierney B, Iqbal A, Haider M, Filipi C. Effects of prior endoluminal gastroplication on subsequent laparoscopic Nissen fundoplication. Surg Endosc 2007;21:321-3.

2. Shaheen NJ, Hansen RA, Morgan DR, et al. The burden of gastrointestinal and liver diseases, 2006. Am J Gastroenterol 2006;101:2128-38.

3. Galmiche JP, Letessier E, Scarpignato C. Treatment of gastro-oesophageal reflux disease in adults. BMJ 1998;316:1720-3.

4. Contini S, Scarpignato C. Endoscopic treatment of gastro-oesophageal reflux disease (GORD): A systematic review. Dig Liver Dis 2003;35:818-38.

5. Kahrilas PJ. Radiofrequency therapy of the lower esophageal sphincter for treatment of GERD. Gastrointest Endosc 2003;57:723-31.

6. Corley DA, Katz P, Wo JM, et al. Improvement of gastroesophageal reflux symptoms after radiofrequency energy: A randomized, sham-controlled trial. Gastroenterology 2003;125:668-76.

7. Lutfi RE, Torquati A, Kaiser J, Holzman M, Richards WO. Three year's experience with the Stretta procedure: Did it really make a difference? Surg Endosc 2005;19:289-95.

8. Tam WC, Schoeman MN, Zhang Q, et al. Delivery of radiofrequency energy to the lower oesophageal sphincter and gastric cardia inhibits transient lower oesophageal sphincter relaxations and gastro-oesophageal reflux in patients with reflux disease. Gut 2003;52:479-85.

9. Triadafilopoulos G, DiBaise JK, Nostrant TT, et al. The Stretta procedure for the treatment of GERD: 6 and 12 month follow-up of the US open label trial. Gastrointest Endosc 2002;55:149-56.

10. Wolfsen HC, Richards WO. The Stretta procedure for the treatment of GERD: A registry of 558 patients. J Laparoendosc Adv Surg Tech A 2002;12:395-402.

11. Beck JR, Pauker SG. The Markov process in medical prognosis. Med Decis Making 1983;3:419-58.

12. Sonnenberg FA, Beck JR. Markov models in medical decision making: A practical guide. Med Decis Making 1993;13:322-38.

13. Ethiopia A, Gregor J, Preiksaitis HR, et al. An evaluation of utility measurement in gastroesophageal reflux disease (GERD). Gastroenterology 1998;114(Suppl 1):A116. (Abst)

14. Haddix AC, Teutsch SM, Corso PS. Prevention Effectiveness. A Guide to Decision Analysis and Economic Evaluation, 2nd edn. Oxford: Oxford University Press, 2003.

15. Canadian Coordinating Office for Health Technology Assessment. Guidelines for economic evaluation of pharmaceuticals: Canada, 2nd edn. Ottawa: Canadian Coordinating Office for Health Technology Assessment, 1997.
The potential for a decrease in PPI costs was identified during study conception and was addressed by sensitivity analysis. Our base case drug price for generic omeprazole ( $\$ 1.25$ per $20 \mathrm{mg}$ tablet) was derived from a national registry.

We chose a reasonable time horizon of five years to study the cost-effectiveness of the Stretta procedure, despite the lack of long-term data on the durability of the Stretta procedure. Published experience to date is limited to three years, but these data do suggest a sustained clinical effect (7). Additional clinical trial-derived and generalizable data are now needed to better determine these important clinical parameters, thus allowing for more confident decision-making.

As generic and cheaper PPI medications become increasingly available in Canada, the cost advantage of the Stretta procedure diminishes. In conclusion, regardless of the units of effectiveness or utility used in the present cost analysis, an approach of prescribing PPIs appears to be more cost-effective than using LNF or the Stretta procedure.

FUNDING: Financial support was provided in part by a research scholarship from the Canadian Association of Gastroenterology, and the Canadian Institutes of Health Research in association with Pentax Precision Instruments.
16. Riewpaiboon A, Malaroje S, Kongsawatt S. Effect of costing methods on unit cost of hospital medical services. Trop Med Int Health 2007;12:554-63.

17. IMS Health Incorporated. Intercontinental Medical Statistics. <http://www.imshealthcanada.com/web/home/0,3153,77303623_63 $872702,00 . \mathrm{html}>$ (Version current at May 9, 2008).

18. Ontario Ministry of Health and Long-Term Care. Schedule of benefits: Physician services under the Health Insurance Act. Toronto: Ontario Ministry of Health and Long-Term Care, 2007.

19. Canadian Institute for Health Information. $<$ http://secure.cihi.ca/ cihiweb/splash.html> (Version current at May 9, 2008).

20. Crott R, Makris N, Barkun A, Fallone C. The cost of an upper gastroduodenal endoscopy: An activity-based approach. Can J Gastroenterol 2002;16:473-82.

21. Harewood GC, Gostout CJ. Cost analysis of endoscopic antireflux procedures: Endoluminal plication vs. radiofrequency coagulation vs. treatment with a proton pump inhibitor. Gastrointest Endosc 2003;58:493-9.

22. Barkun AN, Herba K, Adam V, Kennedy W, Fallone CE, Bardou M. High-dose intravenous proton pump inhibition following endoscopic therapy in the acute management of patients with bleeding peptic ulcers in the USA and Canada: A cost-effectiveness analysis. Aliment Pharmacol Ther 2004; 19:591-600.

23. Briggs AH, Goeree R, Blackhouse G, O’Brien BJ. Probabilistic analysis of cost-effectiveness models: Choosing between treatment strategies for gastroesophageal reflux disease. Med Decis Making 2002;22:290-308.

24. Briggs A, Sculpher M. An introduction to Markov modelling for economic evaluation. Pharmacoeconomics 1998;13:397-409.

25. Fenwick E, O'Brien BJ, Briggs A. Cost-effectiveness acceptability curves - facts, fallacies and frequently asked questions. Health Econ 2004;13:405-15.

26. Gafni A. Willingness-to-pay as a measure of benefits. Relevant questions in the context of public decisionmaking about health care programs. Med Care 1991;29:1246-52.

27. Low DE. Management of the problem patient after antireflux surgery. Gastroenterol Clin North Am 1994;23:371-89.

28. Catarci M, Gentileschi P, Papi C, et al. Evidence-based appraisal of antireflux fundoplication. Ann Surg 2004;239:325-37.

29. U.S. Food and Drug Administration, Center for Devices and Radiological Health. Manufacturer and User Facility Device Experience Database (MAUDE). <http://www.fda.gov/cdrh/ maude.html> (Version current at April 8, 2008). 
30. Drummond MF, Stoddart GL, Torrance GW. Methods for the Economic Evaluation of Health Care Programmes. Oxford: Oxford University Press, 1987.

31. Malhi-Chowla N, Gorecki P, Bammer T, Achem SR, Hinder RA, Devault KR. Dilation after fundoplication: Timing, frequency, indications, and outcome. Gastrointest Endosc 2002;55:219-23.

32. Velanovich V. Medication usage and additional esophageal procedures after antireflux surgery. Surg Laparosc Endosc Percutan Tech 2003;13:161-4.

33. Allen CJ, Anvari M. Preoperative symptom evaluation and esophageal acid infusion predict response to laparoscopic Nissen fundoplication in gastroesophageal reflux patients who present with cough. Surg Endosc 2002;16:1037-41.

34. Hui TT, Fass SM, Giurgiu DI, Iida A, Takagi S, Phillips EH. Gastroesophageal disease and nausea: Does fundoplication help or hurt? Arch Surg 2000;135:545-9.

35. Khoursheed MA, Al-Asfoor M, Al-Shamali M, et al. Effectiveness of laparoscopic fundoplication for gastro-oesophageal reflux. Ann R Coll Surg Engl 2001;83:229-34.

36. Richards WO, Houston HL, Torquati A, Khaitan L, Holzman MD, Sharp KW. Paradigm shift in the management of gastroesophageal reflux disease. Ann Surg 2003;237:638-47; discussion 648-9.

37. Karim SS, Panton ON, Finley RJ, et al. Comparison of total versus partial laparoscopic fundoplication in the management of gastroesophageal reflux disease. Am J Surg 1997;173:375-8.

38. Luketich JD, Fernando HC, Christie NA, et al. Outcomes after minimally invasive esophagomyotomy. Ann Thorac Surg 2001;72:1909-12; discussion 1912-3.
39. Spechler SJ, Lee E, Ahnen D, et al. Long-term outcome of medical and surgical therapies for gastroesophageal reflux disease: Follow-up of a randomized controlled trial. JAMA 2001;285:2331-8.

40. Armstrong D, Barkun AN, Chiba N, et al. On demand therapy for heartburn-dominant uninvestigated dyspepsia (HBDUD) in primary care practice (PCP): The Cadet-Hr study. Can J Gastroenterol 2003;17(Suppl A):105A. (Abst)

41. Gerson LB, Robbins AS, Garber A, Hornberger J, Triadafilopoulos G. A cost-effectiveness analysis of prescribing strategies in the management of gastroesophageal reflux disease. Am J Gastroenterol 2000;95:395-407.

42. Kartman B, Gatz G, Johannesson M. Health state utilities in gastroesophageal reflux disease patients with heartburn: A study in Germany and Sweden. Med Decis Making 2004;24:40-52.

43. Wood HM, Schechtman G. Can utilities measure drug-related toxicity? Med Decis Making 1994;14:443. (Abst)

44. Heudebert GR, Marks R, Wilcox CM, Centor RM. Choice of long-term strategy for the management of patients with severe esophagitis: A cost-utility analysis. Gastroenterology 1997;112:1078-86.

45. Wildi SM, Cox MH, Clark LL, et al. Assessment of health state utilities and quality of life in patients with malignant esophageal Dysphagia. Am J Gastroenterol 2004;99:1044-9.

46. Barkun A, Sabbah S, Enns R, et al; RUGBE Investigators. The Canadian Registry on Nonvariceal Upper Gastrointestinal Bleeding and Endoscopy (RUGBE): Endoscopic hemostasis and proton pump inhibition are associated with improved outcomes in a real-life setting. Am J Gastroenterol 2004;99:1238-46. 


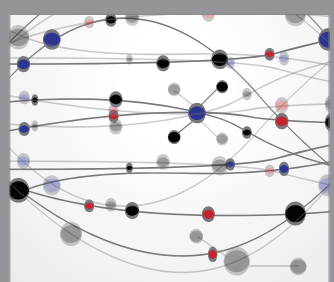

The Scientific World Journal
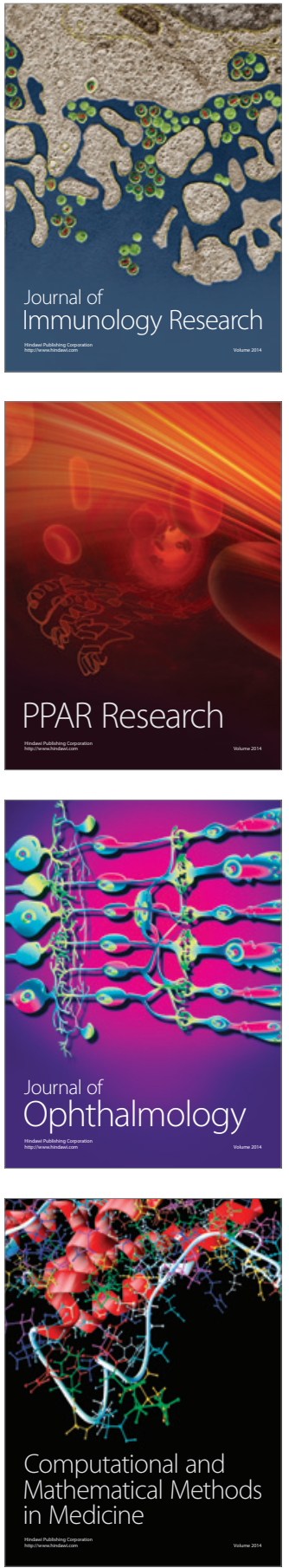

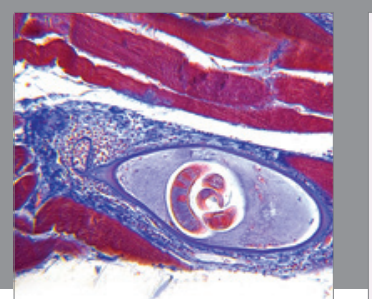

Gastroenterology Research and Practice

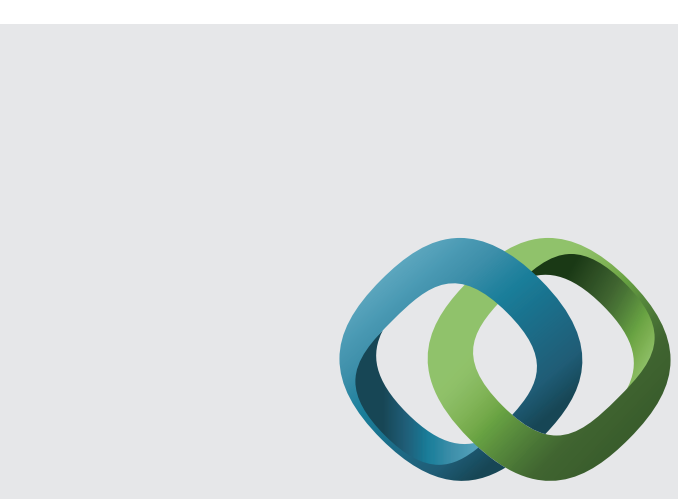

\section{Hindawi}

Submit your manuscripts at

http://www.hindawi.com
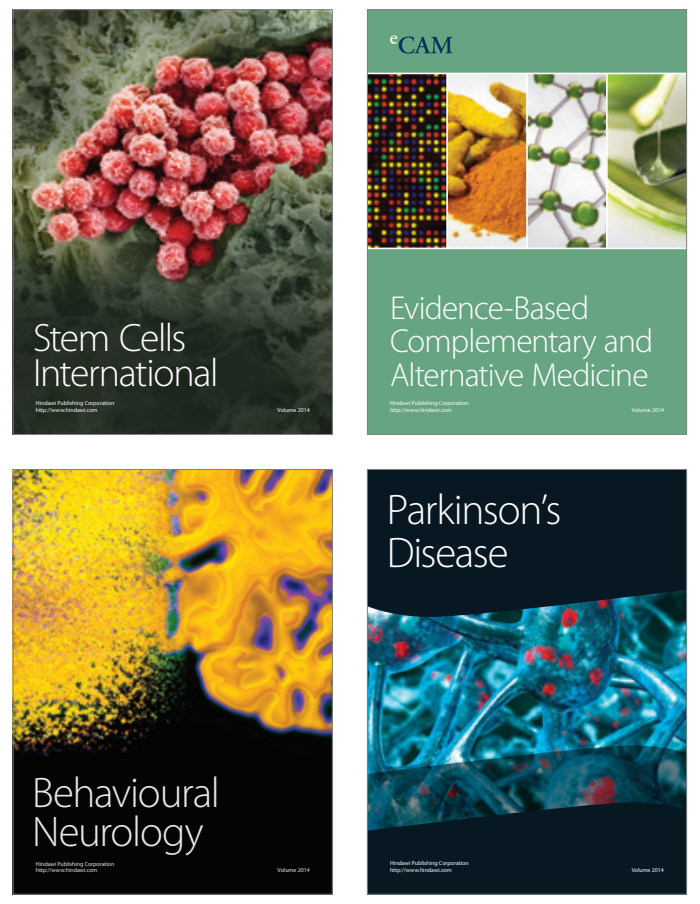
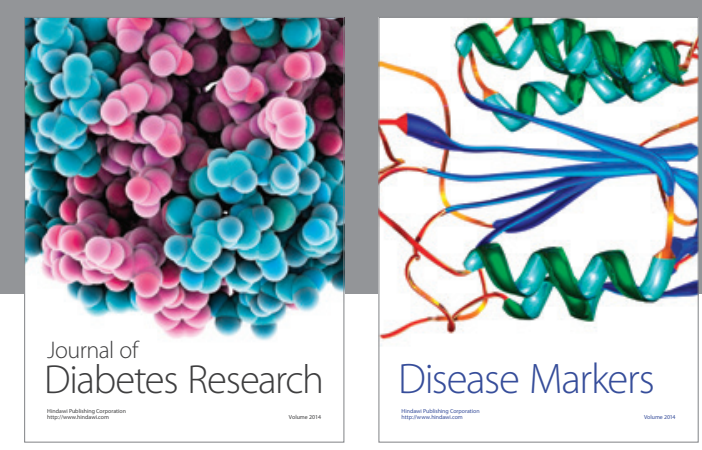

Disease Markers
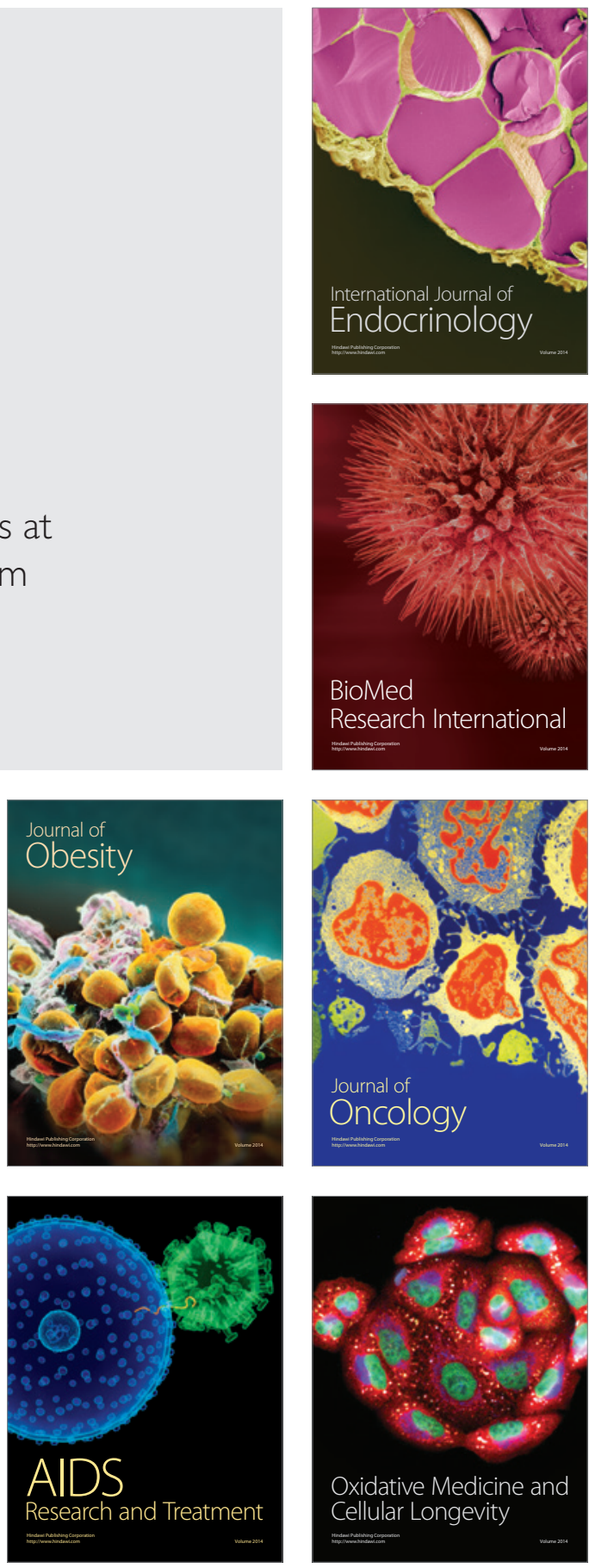